\title{
Notes on the vocalizations of Paramo Seedeater (Catamenia homochroa)
}

Peter Boesman

In the following we briefly analyze and compare voice of the three races of Paramo Seedeater (Catamenia homochroa). We also try to quantify the extent of any vocal differences using the criteria proposed by Tobias et al. (2010), as a support for taxonomic review. We have made use of sound recordings available on-line from Xeno Canto (XC) and Macaulay Library (ML).

Relatively few recordings of song are available. An overview per race, illustrated with sonograms:

oreophila (Santa Marta, Colombia)
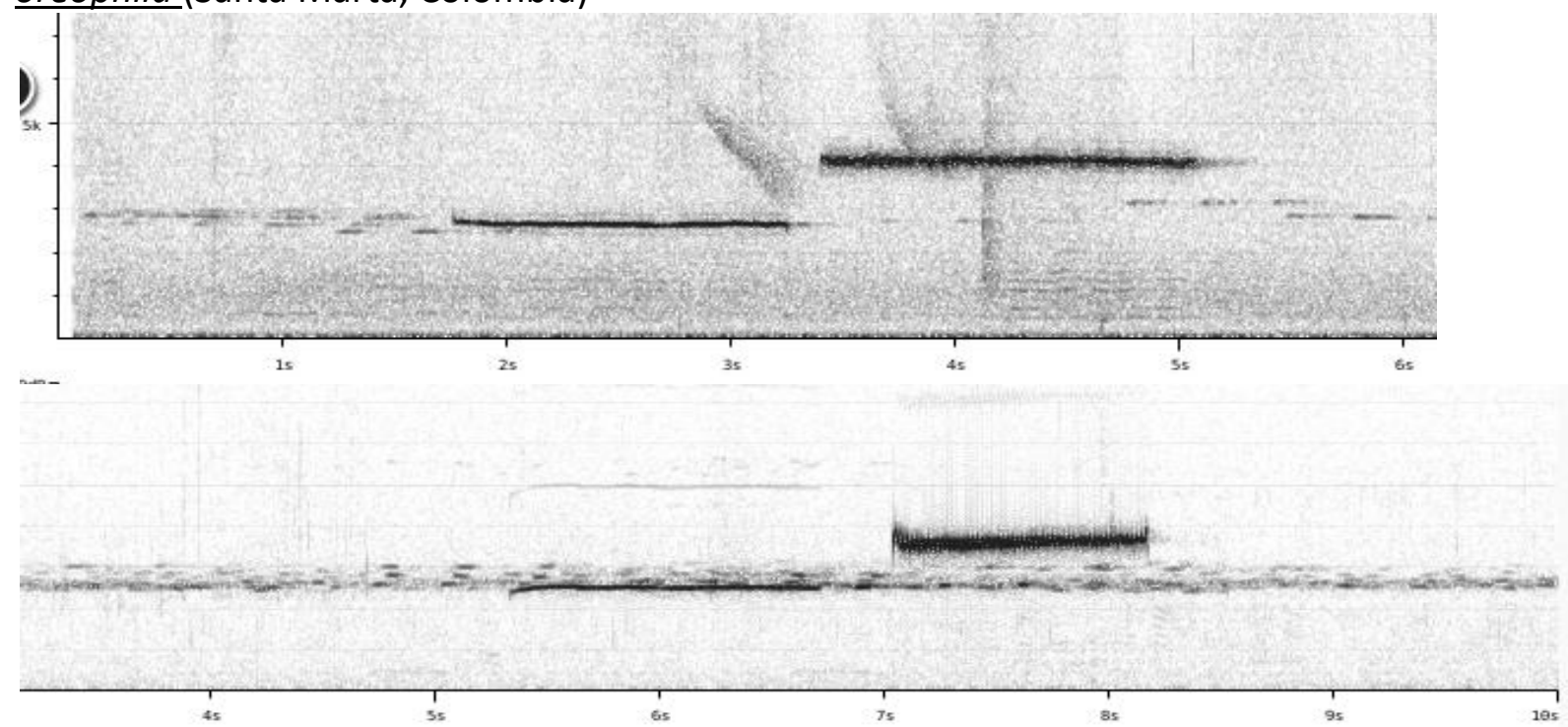

$\underline{\text { nominate }}$

Perija mountains, Colombia/Venezuela

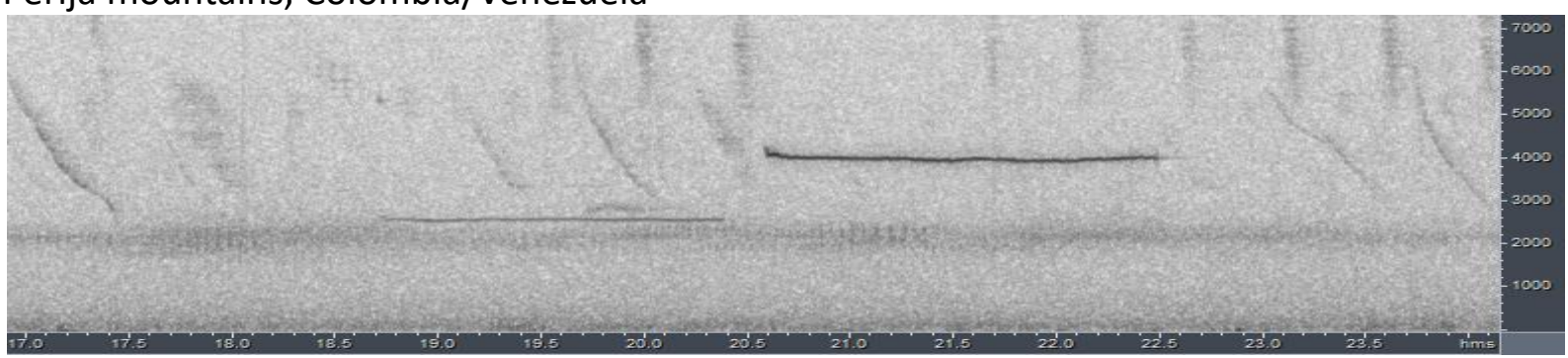

NW Colombia

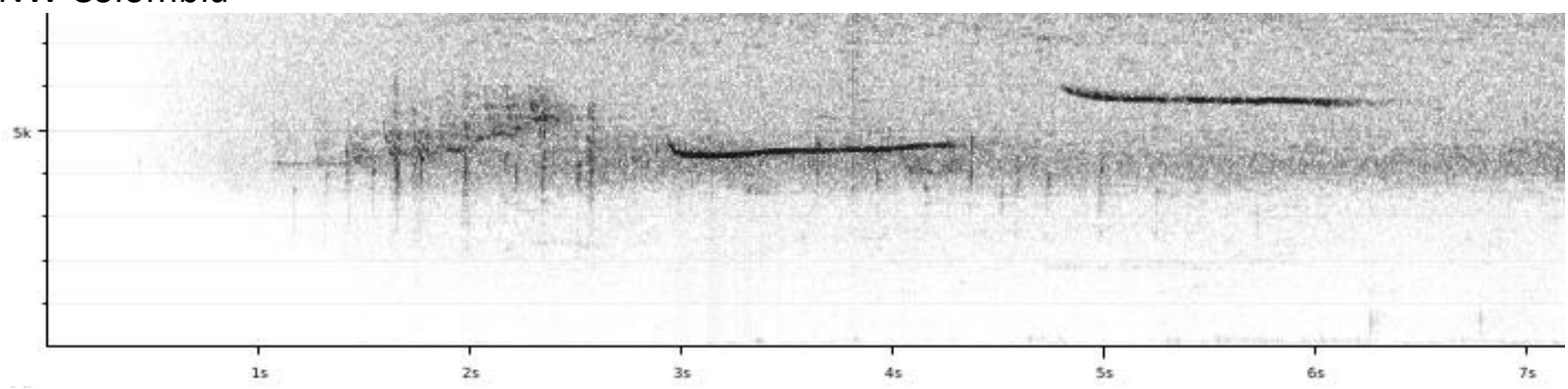




\section{HANDBOOK OF THE \\ BIRDAPlu WU WRLD ORNITHOLOGICAL NOTES}

\section{Ecuador}

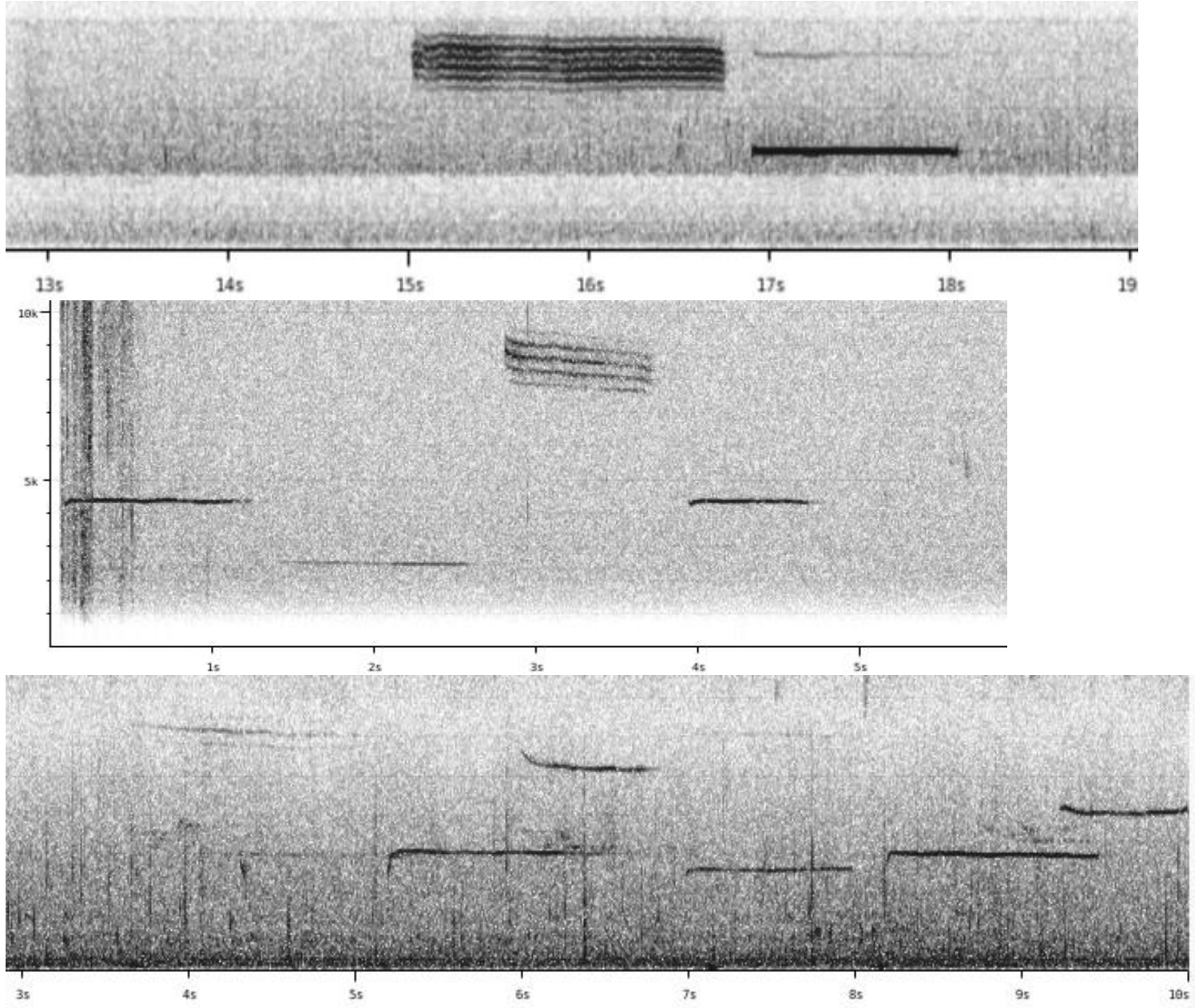

Peru

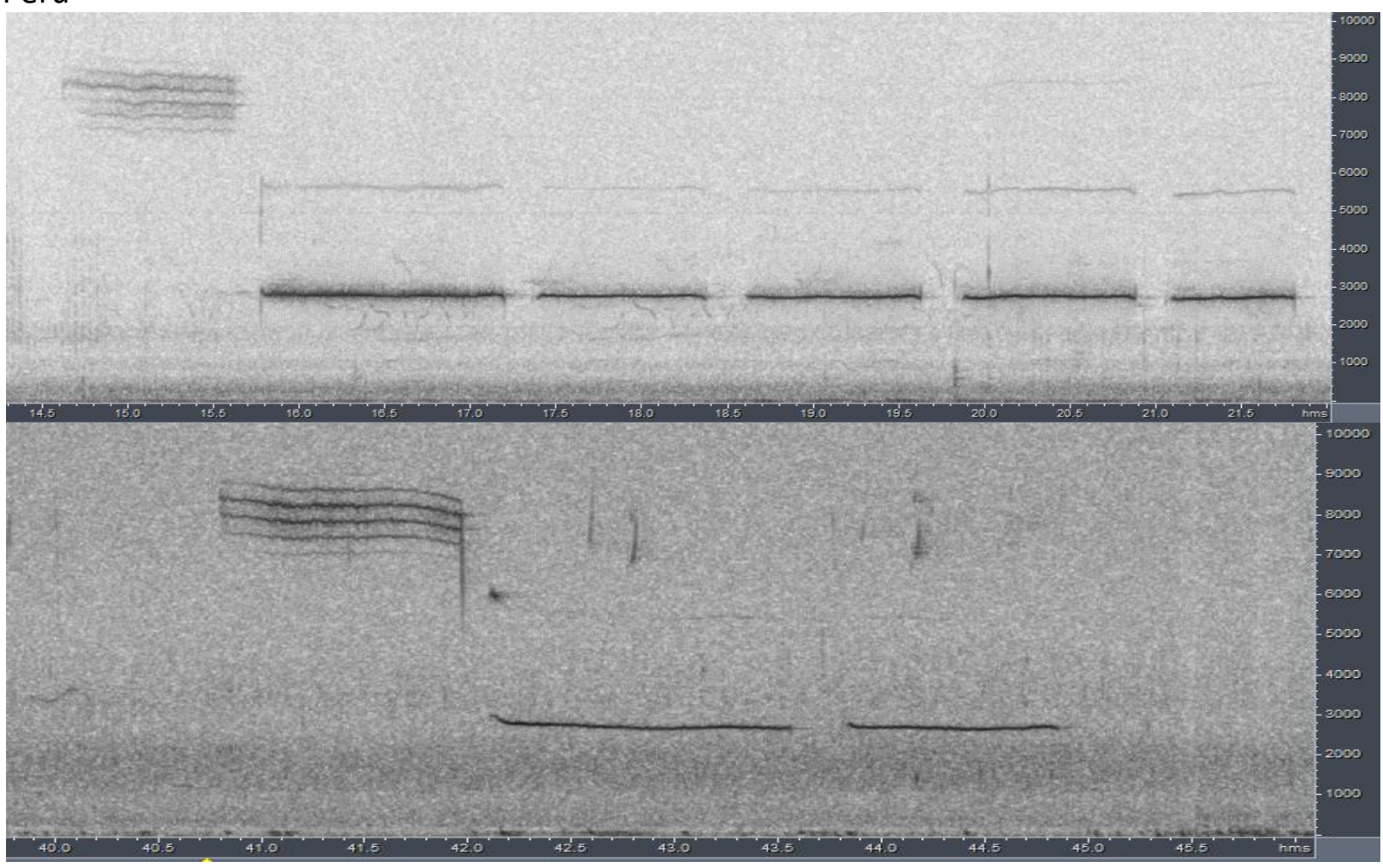



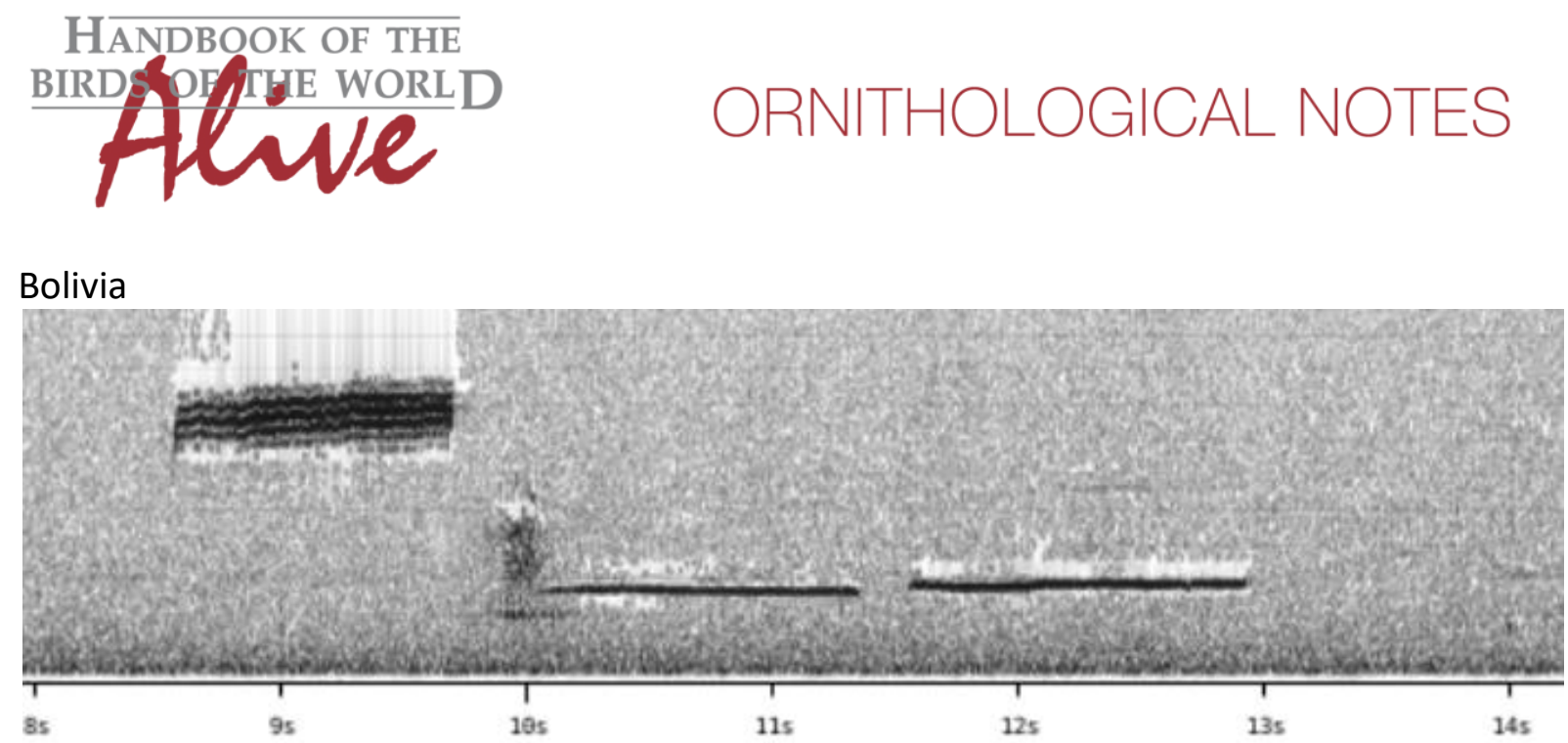

\section{duncani}

There are no recordings of song available for this race. It is unclear what is the source of the voice description in HBW Alive ("duncani sings a low-pitched whistle", Jaramillo 2016), as the main source for Venezuelan birds lacks description of song (Hilty 2003). In any case, without a quantification of the pitch, it is not possible to determine whether this is a difference with other races or not.

Song of all races is a sequence of long (1-2s) flat-pitched whistles, with occasional changes in pitch (or two males may sing at different pitch).

Song of populations in the Santa Marta (orephila) and Perija mountains (nominate) is very similar.

Birds of $(N)$ Colombia seemingly lack the high-pitched buzzy notes, while almost all recordings from Ecuador, Peru and Bolivia do have such buzzy notes in the song.

More recordings would be needed to determine whether there are any consistent vocal differences between races or populations, but based on the available recordings these are expected to be rather minor, at least between orephila and nominate.

This note was finalized on 30th June 2016, using sound recordings available on-line at that moment. We would like to thank in particular the sound recordists who placed their song recordings for this species on XC and ML: Peter Boesman, Diego Calderon, Paul Coopmans, Andres Cuervo, Sebastian Herzog, Niels Krabbe, Lars Lachmann, Mitch Leisinger, Ted Parker, Thomas Schulenberg, Andrew Spencer and Benjamin Winger.

\section{References}

Hilty, S. L. (2003) Birds of Venezuela. Helm Field Guides. Christopher Helm, London.

Jaramillo, A. (2016). Paramo Seedeater (Catamenia homochroa). In: del Hoyo, J., Elliott, A., Sargatal, J., Christie, D.A. \& de Juana, E. (eds.). Handbook of the Birds of the World Alive. Lynx Edicions, Barcelona. (retrieved from http://www.hbw.com/node/62149 on 30 June 2016). 


\section{Recommended citation}

Boesman, P. (2016). Notes on the vocalizations of Paramo Seedeater (Catamenia homochroa). HBW Alive Ornithological Note 392. In: Handbook of the Birds of the World Alive. Lynx Edicions, Barcelona. (retrieved from http://www.hbw.com/node/1253581 on 1 December 2016). 